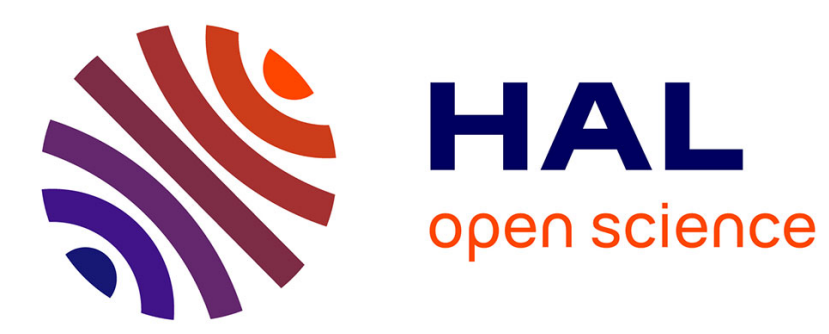

\title{
Predicted and observed magnetic signatures of Martian (de)magnetized impact craters
}

Benoit Langlais, Erwan Thébault

\section{To cite this version:}

Benoit Langlais, Erwan Thébault. Predicted and observed magnetic signatures of Martian (de)magnetized impact craters. Icarus, 2011, 212 (2), pp.568. 10.1016/j.icarus.2011.01.015 . hal00734586

\section{HAL Id: hal-00734586 \\ https://hal.science/hal-00734586}

Submitted on 24 Sep 2012

HAL is a multi-disciplinary open access archive for the deposit and dissemination of scientific research documents, whether they are published or not. The documents may come from teaching and research institutions in France or abroad, or from public or private research centers.
L'archive ouverte pluridisciplinaire HAL, est destinée au dépôt et à la diffusion de documents scientifiques de niveau recherche, publiés ou non, émanant des établissements d'enseignement et de recherche français ou étrangers, des laboratoires publics ou privés. 


\section{Accepted Manuscript}

Predicted and observed magnetic signatures of Martian (de)magnetized impact craters

Benoit Langlais, Erwan Thébault

PII:

S0019-1035(11)00026-1

DOI:

10.1016/j.icarus.2011.01.015

Reference:

YICAR 9694

To appear in:

Icarus

Received Date: 3 May 2010

Revised Date: $\quad 6$ January 2011

Accepted Date: $\quad 6$ January 2011

Please cite this article as: Langlais, B., Thébault, E., Predicted and observed magnetic signatures of Martian (de)magnetized impact craters, Icarus (2011), doi: 10.1016/j.icarus.2011.01.015

This is a PDF file of an unedited manuscript that has been accepted for publication. As a service to our customers we are providing this early version of the manuscript. The manuscript will undergo copyediting, typesetting, and review of the resulting proof before it is published in its final form. Please note that during the production process errors may be discovered which could affect the content, and all legal disclaimers that apply to the journal pertain. 


\section{Predicted and observed magnetic signatures}

\section{of Martian (de)magnetized impact craters}

Benoit Langlais ${ }^{\mathrm{a}}$, Erwan Thébault ${ }^{\mathrm{b}}$

${ }^{\mathrm{a}}$ CNRS UMR 6112, Université de Nantes, Laboratoire de Planétologie et

Géodynamique, 2 Rue de la Houssinière, Nantes, F-44000, France

${ }^{\mathrm{b}}$ CNRS UMR 7154, Institut de Physique du Globe de Paris, Équipe de

Géomagnétisme, 1 Rue Cuvier, F-75005 Paris, France

Copyright (C) 2011 Benoit Langlais and Erwan Thébault

Number of pages: 31

Number of figures: 9 


\section{Proposed Running Head:}

Magnetic signatures of large impact structures on Mars

Please send Editorial Correspondence to:

Benoit Langlais

CNRS UMR 6112

Université de Nantes

Laboratoire de Planétologie et Géodynamique

2 rue de la Houssinière

44322 Nantes cedex

France

Email: benoit.langlais@univ-nantes.fr

Phone: +33(0)251 125497

Fax: $+33(0) 251125268$ 


\section{ABSTRACT}

The current morphology of the Martian lithospheric magnetic field results from magnetization and demagnetization processes, both of which shaped the planet. The largest Martian impact craters, Hellas, Argyre, Isidis and Utopia, are not associated with intense magnetic fields at spacecraft altitude. This is usually interpreted as locally non- or de-magnetized areas, as large impactors may have reset the magnetization of the pre-impact material. We study the effects of impacts on the magnetic field. First, a careful analysis is performed to compute the impact demagnetization effects. We assume that the pre-impact lithosphere acquired its magnetization while cooling in the presence of a global, centered and mainly dipolar magnetic field, and that the subsequent demagnetization is restricted to the excavation area created by large craters, between 50- and 500-km diameter. Depth-to-diameter ratio of the transient craters is set to 0.1 , consistent with observed telluric bodies. Associated magnetic field is computed between 100 - and $500-\mathrm{km}$ altitude. For a single-impact event, the maximum magnetic field anomaly associated with a crater located over the magnetic pole is maximum above the crater. A 200-km diameter crater presents a close-to-1-nT magnetic field anomaly at 400-km altitude, while a 100-km diameter crater has a similar signature at 200-km altitude. Second, we statistically study the 400-km altitude Mars Global Surveyor magnetic measurements modelled locally over the visible impact craters. This approach offers a local estimate of the confidence to which the magnetic field can be computed from real measurements. We conclude that currently craters down to a diameter of $200 \mathrm{~km}$ can be characterized. There is a slight anti correlation of -0.23 between magnetic field intensity and impact crater diameters, although we show that this result may be fortuitous. A complete low-altitude 
magnetic field mapping is needed. New data will allow predicted weak anomalies above craters to be better characterized, and will bring new constraints on the timing of the Martian dynamo and on Mars' evolution.

Keywords:

Mars, surface; Mars, interior; Impact processes; Magnetic fields 


\section{Introduction}

The present day magnetic field of Mars as it was measured by the Mars Global Surveyor (MGS) probe (Acuña et al., 1998) has a remanent origin. Its geographical distribution is heterogeneous, most intense fields being found South of the crustal dichotomy, within Terra Cimmeria and Terra Sirenum (Connerney et al., 1999). The magnetic field of Mars is intriguing as it is about 1 to 2 orders of magnitude larger than the Earth's lithospheric field (Thébault et al., 2010), which comes in excess or in deficit to the main magnetic field of core origin as an anomalous field. It is also larger than any other known planetary magnetic field of lithospheric origin (Langlais et al., 2010). It exceeds 1500 nT at 90-km altitude (Acuña et al., 1999) and its radial component ranges between $\pm 250 \mathrm{nT}$ at a constant altitude of $400 \mathrm{~km}$ (Cain et al., 2003).

The existence of a Martian lithospheric field provides us with an important tool for remotely investigating the properties of the Martian magnetizated crust and of the extinct dynamo. The remanent magnetization is borne by magnetic minerals, which are present in the upper part of the Martian lithosphere. Both magnetization (when the dynamo was active) and demagnetization processes (posterior to the dynamo cessation) concurred to give the current Martian magnetic field. The lack of significant magnetic field above impact-related Hellas basin or volcanic edifices of Tharsis Bulge was early interpreted as a cessation of the dynamo prior to these destructive events, i.e., volcanic eruption or crater emplacement (Acuña et al., 1999). The magnetic properties of minerals can indeed be altered or erased by several processes, including reheating, shock, or large scale brecciation. There have been many attempts to parameterize the relationship between apparent weak or null magnetiza- 
tion and large impact craters or basins (Nimmo and Gilmore, 2001; Rochette et al., 2003; Hood et al., 2003; Mohit and Arkani-Hamed, 2004; Artemieva et al., 2005; Shahnas and Arkani-Hamed, 2007). Assuming the magnetic carrier is mainly pyrrhotite, Hood et al. (2003) suggested that shock demagnetization may reach 3 to 4 basin radii, while Mohit and Arkani-Hamed (2004) concluded that thermal and shock demagnetization is likely to affect the whole lithosphere within only about 0.8 basin radius, and the upper part only up to 1.4 basin radius. Such differences arise because it is difficult to accurately parameterize both the impactor characteristics (velocity, size, and composition) and the lithosphere properties (magnetic mineral phase, composition, thickness, magnetization intensity and directions).

The timing of the dynamo cessation is a critical issue on Mars because it directly constrained the protection of an atmosphere. Using early measurements of the MGS mission, Nimmo and Gilmore (2001) studied the signature of large $(>500 \mathrm{~km})$ impact structures, and concluded that such craters had significantly lower magnetic field signatures than smaller craters. Lillis et al. (2008a) studied a limited number of visible or buried basins larger than 1000 $\mathrm{km}$. They observed that some basins were correlated with large magnetic fields, while others were not, and compared their magnetic signatures to a crater timeline (Frey, 2008). They concluded from the very different signature of impact craters having similar ages that the dynamo shut down very quickly, about 4.12 Ga ago (model age). However, this inferred early dynamo cessation has been recently challenged because some younger structures on Mars are still magnetized. Some younger volcanic edifices, such as Hadriaca Patera (Lillis et al., 2006), or Apollinaris Patera (Langlais and Purucker, 2007), display magnetic signatures. The latter was studied by Hood et al. (2010), 
who demonstrated that a concentration of magnetization centered on the construct is the most likely explanation. The magnetization of the young (3.7 Ga, Werner (2009)) volcanic edifice suggests that a martian dynamo existed after the major basin-forming impacts and the formation of the northern lowlands. This is also the conclusion of the statistical analysis conducted by Milbury and Schubert (2010) who reported very small differences between Noachian and Hesperian units, indicating a dynamo persisting during the Hesperian.

Our study aims at revisiting the postulate that the magnetic structures over very large impact craters only can be accurately characterized by measurements made onboard spacecrafts. We chose to investigate qualitatively and quantitatively the demagnetization associated with the impact excavation process, as this is the only volume where demagnetization occurs regardless of the impactor or lithosphere physical properties. This allows us to tackle a secondary but important question regarding the ability of available (or future) spacecraft measurements to characterize impact crater magnetic signatures on Mars. We address these questions through a dual approach. We first use a forward modeling scheme to predict the shape and the strength of the magnetic field above idealized demagnetized impact craters with varying parameters (basin radius, location, pre-impact magnetized thickness, and observation altitude). We then consider Martian magnetic field models, and also solve the inverse problem over large impact craters using the magnetic field measurements of the MGS mission. These comparisons allow us to draw some statistical conclusions regarding the proper use of MGS measurements for inferring physical properties from the observed magnetic field of Mars above craters. We finally discuss these results in the perspective of future complementary and necessary magnetic field measurements around Mars. 


\section{Forward Modeling Scheme}

We begin our study with a pure forward modeling approach in order to investigate the magnetic signature associated with large and demagnetized impact craters at different altitudes. Impact demagnetization effects are evaluated by reducing the thickness of the magnetized lithosphere. We describe the method and the different assumptions. Remagnetization processes are omitted, because only excavation consequences on the magnetic field are considered here.

\subsection{Method}

We assume that the impact craters are emplaced in a pre-impact magnetized lithosphere, which is described by Equivalent Source Dipoles (ESD) (Purucker et al., 1996): dipoles are placed onto a equidistant grid using 'polar coordinates subdivision' (Katanforoush and Shahshahani, 2003). We considered a very dense mesh, with a mean horizontal distance between adjacent dipole sources set to $4 \mathrm{~km}$. The thickness of each ESD shell is set to the same value. The entire magnetized layer consists of a the vertical superposition of several ESD layers.

Two end-members scenarios, homogeneous or heterogenous, can be proposed for the crust formation and magnetization acquisition. First, a continuous homogeneous crust formation, in which the crust cooled down globally and gradually in the presence of a dynamo. If the magnetic field reversed, then alternate polarities are to be found as one goes deeper in the crust, resulting in weak, or even null, total magnetization over the whole lithosphere thickness in the case of a fast cooling rate or frequent reversals (Rochette, 2006). 
If the magnetic field was stable (or if the cooling rate was slow), then following Runcorn's theorem the resulting magnetization does not produce any magnetic field outside the spherical shell after the dynamic field has disappeared (Runcorn, 1975). Second, the crust may have formed heterogeneously in space and time. While forming, blocks or units of various sizes and at various locations acquired a magnetization aligned onto the existing dynamo. The resulting magnetization (and associated magnetic field signature) is then proportional to both the typical wavelength of the dynamo field at Mars' surface and to the characteristics of the crust formation both in time and space. In our study, we consider the continuous and homogeneous crust formation assumption. Only perturbations from the spherical shell, such as topographic elevations (volcanoes) or lows (craters) are associated with magnetic fields. This asumption is geophysically simplistic, but the necessary information to address this problem in a more realistic way is not available. Our ambition is not to reproduce the actual observations, but rather to put limits on the size of craters which may produce measurable magnetic field anomalies at various spacecraft altitudes.

\subsection{Magnetization directions and magnitude}

For simplicity, we assume that the magnetization was acquired in the presence of a dipolar centered dynamo. Inclination (angle between the horizontal and the magnetization vector) therefore directly relies on the magnetic latitude $\lambda_{\text {mag }}$. Around the magnetic equator inclination varies from -7 to $+7^{\circ}$ over a 400-km distance. Declination (angle between the geographical North and magnetization vector) is zero everywhere when the magnetic and rotation 
poles are collocated (i.e., for an axial centered dipolar paleomagnetic field), but it takes different values otherwise. There have been many attempts to characterize the Martian paleomagnetic field, in terms of magnetic pole location (Arkani-Hamed, 2001; Boutin and Arkani-Hamed, 2006; Frawley and Taylor, 2004; Hood et al., 2005; Langlais and Purucker, 2007; Quesnel et al., 2007). Many proposed a magnetic paleopole that was different from the geographical rotation pole. We therefore test the two extreme configurations, at the magnetic pole and at the magnetic equator.

Magnetization intensity also increases with the depth of the magnetized layer (as the distance from the core decreases). Provided that the considered minerals are located above the Curie isotherm, magnetization intensity can increase by $3 \%$ between the surface and a depth of $40 \mathrm{~km}$. More importantly, the magnetization intensity varies with respect to the magnetic latitude, so that:

$$
M\left(\lambda_{\text {mag }}\right)=A\left(1+\sin ^{2}\left(\lambda_{\text {mag }}\right)\right)^{1 / 2}
$$

where $A$ is some constant (in $\mathrm{A} \cdot \mathrm{m}^{-1}$ ) representing the magnetization at the magnetic equator. There are few estimates of the Martian magnetization intensity. Langlais et al. (2004) computed an ESD model using 4840 equidistant dipoles representing a 40-km thick magnetized spherical shell. In their model, magnetization component values $M_{r}$ (radial), $M_{\theta}$ (horizontal southward) and $M_{\phi}$ (horizontal eastward) range between $\pm 12 \mathrm{~A} \cdot \mathrm{m}^{-1}$; the mean intensity value is only $0.8 \mathrm{~A} \cdot \mathrm{m}^{-1}$, but it increases to 1.2 when considering the southern, magnetized, hemisphere only. Whaler and Purucker (2005) used different assumptions and modeling techniques and reached a similar conclusion, with a mean magnetization intensity of $0.93 \mathrm{~A} \cdot \mathrm{m}^{-1}$. The only direct estimate of the Martian magnetization, from the ALH84001 meteorite, was reported by Weiss 
et al. (2002): values ranging between 0.1 and $1.6 \mathrm{~A} \cdot \mathrm{m}^{-1}$ were found. Magnetization may of course locally exceed these values: Parker (2003) concluded that the magnetization must exceed $4.76 \mathrm{~A} \cdot \mathrm{m}^{-1}$ within Terra Cimmeria and Terra Sirenum to account for the MGS observations. In the following we choose a constant $A=1 \mathrm{~A} \cdot \mathrm{m}^{-1}$, consistent with the above mentioned studies. This value has to be seen as a nominal value, from which scaling to actual and possibly locally larger Martian magnetization can be done.

The thickness of the pre-impact magnetized layer has also to be taken into account. This parameter depends on the magnetic mineralogy as well as on the surface temperature and temperature gradient of the lithosphere when the magnetization was acquired. We choose to test different magnetization thicknesses, up to $60 \mathrm{~km}$. This value should be regarded as a maximum value, and not as the real one. It is deduced from estimates of the thermal gradient during Noachian times (McGovern et al., 2004a,b), ranging from 10 to 30 ${ }^{\circ} \mathrm{C} \cdot \mathrm{km}^{-1}$ and assuming a surface temperature of $0^{\circ} \mathrm{C}$ (Quesnel et al., 2009).

\subsection{Crater Parameters}

When forming, an impact crater is first associated with an approximately hemispherical cavity. After some maximum depth $d_{t}$ is reached (due to the resistance of the underlying pre-impact lithosphere), the cavity continues to expand laterally. The final crater is thus larger than a hemisphere, and can be approximated by a paraboloid of revolution of diameter $D_{t}$. This crater is often referred to as a transient crater, since it is later modified by gravity and collapse effects (Melosh, 1989). This transient crater defines the cavity in which the pre-impact material has been affected during the impact process: immedi- 
ately below the impactor some material is compressed and pushed downward, while in other areas rocks and minerals are ejected. Depth-to-diameter ratios for transient craters range between $1 / 4$ and $1 / 3$. The excavation diameter $D_{e x}$ is equivalent to the transient diameter, but the excavation depth $d_{e x}$ is smaller than the transient depth $d_{t}$. Based on experiments, numerical computations and observations, the excavation depth is estimated to be about $1 / 3$ of the transient crater depth, or about 1/10 of the transient crater diameter (Croft, 1981; O'Keefe and Ahrens, 1993). The crater is subsequently modified to reach the final observed compensated crater, which is characterized by its rim-to-rim diameter $D_{r}$ and its depth $d_{r}$.

Those quantities are directly observable and measurable from photographs or obtained from topography models. They might be very different from the transient crater parameters; this is especially true for large and complex impact craters, for which gravity plays an important role. Croft (1985) studied terrestrial and lunar complex craters, and gave an empirical relationship between transient and final crater diameters:

$$
D_{t}=D_{Q}^{0.15 \pm 0.04} D_{r}^{0.85 \pm 0.04}
$$

where $D_{Q}$ is the simple-to-complex crater transition diameter. This quantity is a function of $1 / g$, where $g$ is the surface gravitational acceleration. On Mars, this transition diameter is $8 \mathrm{~km}$ (Garvin and Frawley, 1998). This leads to the relationship

$$
D_{t}=1.37 \pm 0.15 D_{r}^{0.85 \pm 0.04}
$$

There is a controversy about the possible decrease of the 1/10 depth-to- 
diameter ratio as the diameter of the crater increases (Melosh, 1989). Before describing our computations, we review different results reported by several studies and present them in Figure 1. Wieczorek and Phillips (1999) studied the gravity signature of large, multi-ring, near side lunar impact craters to reconstruct the excavation cavities. They estimated the excavation depth-todiameter ratio of these impact craters to be $0.115 \pm 0.005$ for eight craters, with diameters ranging between 200 and $500 \mathrm{~km}$. This ratio is lower only for the very large basins (Serenitatis, $D_{e x}=650 \mathrm{~km}$; Imbrium, $D_{e x}=750 \mathrm{~km}$; South Pole-Aitken, $\left.D_{e x}=2100 \mathrm{~km}\right)$. In addition, their results in terms of final and transient diameters are in complete agreement with Eq. (2), with a lunar simple-to-complex transition diameter equal to $15 \mathrm{~km}$. Potts and von Frese (2003) studied the free-air gravity and terrain-correlated anomalies associated with both near and far side lunar impact basins. Their results agree with the previously found $\simeq 0.1$ ratio. Heather and Dunkin (2003) studied the 75-km King crater, one of the freshest large impact crater on the far side of the Moon. They concluded from different observations that deep-seated material, up to $14 \mathrm{~km}$ in depth, had been excavated and exposed by the impact, with a corresponding depth-to-diameter ratio of 0.19 . Impact craters on other planets and bodies were also studied. Using Mariner 10 photographs, Barlow et al. (1999) analyzed the morphology of 61 Hermean fresh and complex craters. They concluded that depth-to-diameter ratios were on average 0.10. Grieve et al. (1981) computed the depth of the disturbed zone for large and complex terrestrial craters by estimating the amount of structural uplift experienced by the deepest material exposed by the impact. They concluded that the depth-to-diameter ratio of the excavation cavity ranges between 0.09 and 0.12. Potts et al. (2004) studied Martian craters using techniques of Potts and von Frese (2003). The excavation depth-to-diameter ratio they deduced from 
gravity field anomalies is 0.09. Pan, the largest impact crater on Amalthea, the third moon of Jupiter, is $90-\mathrm{km}$ wide and 8 -km deep, which is very close to this $1 / 10$ ratio. It shows other craters, all having depth-to-diameter ratios ranging between 0.06 and 0.17 (Thomas et al., 1998).

[Fig. 1 somewhere here]

These independent studies confirm that the ratio between the excavation depth and the transient diameter seems to be relatively independent of the scale, at least in the 100 - $500 \mathrm{~km}$ diameter range. In this study, we conservatively adopt a 0.1 ratio. We assume the demagnetization area to be confined within this excavation cavity. This indeed is the smallest volume that is demagnetized by an impact. This furthermore prevents our study and associated results to be mineralogy dependent. Given the 0.1 ratio between crater diameter and excavation depth, a 200-km wide crater affects the whole magnetized layer if it is $20-\mathrm{km}$ thick, while only one third of it is excavated if it is initially $60-\mathrm{km}$ thick. A 200-km diameter crater is described by 5907 dipoles, while a $500-\mathrm{km}$ diameter crater is described by up to 82594 dipoles, depending on the depth of the magnetized layer.

\section{Predicted magnetic fields}

In the following we present the results associated with varying parameters such as pre-impact magnetization, crater diameter, and thickness of the pre-impact magnetized layer, at different altitudes. However, we alternatively impose one parameter while varying others. 


\subsection{Influence of pre-impact magnetization directions}

The pre-impact magnetization controls the shape of the resulting magnetic field signal, mainly through the magnetization direction. Above the magnetic pole, where the field lines are more or less vertical, the magnetic signature is stronger than above the magnetic equator, where field lines are more or less horizontal. We test two configurations, above the magnetic pole and above the magnetic equator. Any other configuration will lie between these two.

As magnetization intensity varies by a factor of 2 between the pole and the equator, we chose to normalize the magnetization above each crater so that its mean intensity is $1 \mathrm{~A} \cdot \mathrm{m}^{-1}$, in order to ease the comparison between the two different cases. The magnetic field signature consequently depends only on the magnetization direction, not on the initial magnetization intensity.

We show in Fig. 2 the predicted magnetic field (radial component and total intensity) at an altitude of $400 \mathrm{~km}$. In order to focus on the relationship between the paleopole location and the location of the crater, other parameters are set to $200 \mathrm{~km}$ for the crater diameter and to $60 \mathrm{~km}$ for the thickness of the pre-impact magnetized layer. The magnetic field is predicted over a $30^{\circ} \times 30^{\circ}$ area, i.e., up to $1235 \mathrm{~km}$ away from the crater center.

[Fig. 2 somewhere here]

As expected, the magnetic field is stronger when the crater is emplaced within a radially magnetized layer, i.e., at the magnetic pole. At 400-km altitude, the magnetic intensity above such a crater reaches $0.88 \mathrm{nT}$. It decreases to 0.45 nT above the magnetic equator. The shape of the anomaly also changes, from 
a perfectly circular anomaly to an anti-symmetric radial anomaly associated with an elongated total field anomaly. Although not clearly visible on the Fig. 2 , there are two total field maximas, each one about $1.3^{\circ}$ away from the crater center. The zero-contour for the radial anomaly represents the magnetic equator, and is perpendicular to the elongated total field anomaly. Depending on its magnetic paleolatitude (i.e., the paleopole location of the assumed centered dipolar paleomagnetic field of Mars), a 200-km diameter crater has an estimated radial magnetic field signature between $0.5 \mathrm{nT}$ and $0.9 \mathrm{nT}$ at $400-\mathrm{km}$ altitude.

\subsection{Influence of the crater diameter}

The second important parameter is the crater diameter. As described in the previous section, the crater diameter controls the excavation depth. We test a number of crater diameters; these are set to $50 \mathrm{~km}, 75 \mathrm{~km}$, and from 100 to $500 \mathrm{~km}$, with a $50-\mathrm{km}$ increment. Corresponding excavation depths range from 5 to $50 \mathrm{~km}$. The pre-impact magnetized layer is $60-\mathrm{km}$ thick.

The field is again predicted at a 400-km altitude. This allows an easier comparison with the previous subsection. Results are shown in Fig. 3 for the two considered cases. Radial component and total field are shown along a northsouth profile centered above the crater. This is roughly equivalent to the path of a polar orbiting spacecraft. At 400-km altitude the maximum radial magnetic field associated with a $150-\mathrm{km}$ diameter emplaced at the magnetic pole is $0.4 \mathrm{nT}$, but it increases to 0.9, 1.6 and $4.0 \mathrm{nT}$ for $200-\mathrm{km}, 250-\mathrm{km}$ and $350-\mathrm{km}$ diameter craters, respectively. The total field reaches similar intensities, but with wider peaks: the horizontal $B_{\theta}$ component adds up to the radial field 
everywhere except at the magnetic pole where it is zero, while the horizontal $B_{\phi}$ component is null along that trajectory.

[Fig. 3 somewhere here]

The situation is different when the magnetization is horizontal. The radial field changes its polarity at the magnetic equator. The horizontal $B_{\theta}$ component is maximum above the magnetic equator. This combines to produce a total field anomaly which shows two extrema located north and south of the crater center, but still inside the crater area. Field amplitudes are lower than in the radial magnetization case: $150-\mathrm{km}, 200-\mathrm{km}, 250-\mathrm{km}$, and 350-km diameter craters are associated with total field anomalies of up to $0.2,0.4,0.8$, and $2.0 \mathrm{nT}$, respectively. The difference between the maximum field and the one above the center of the crater is on the order of $0.1 \mathrm{nT}$ for a $350-\mathrm{km}$ diameter crater, with a north-south separation of $3^{\circ}$. This field difference increases for larger craters, as will described in the Section 3.4. At 400-km observing altitude, the magnetic field signature of craters with diameters ranging from $150-\mathrm{km}$ to $500-\mathrm{km}$ varies from $0.4 \mathrm{nT}$ to $9.4 \mathrm{nT}$ for a crater located over the magnetic paleopole and from $0.2 \mathrm{nT}$ to $4.6 \mathrm{nT}$ for a crater located above the paleoequator.

\subsection{Influence of the magnetized layer thickness}

In the previous tests we assumed that the demagnetization associated with the impact crater affected the whole magnetized layer, i.e. that the pre-impact magnetized lithosphere was thicker than the impact-related excavation depth. We now let the thickness of magnetized layer vary between 4 and $60 \mathrm{~km}$, while 
imposing the crater diameter and the pre-impact magnetization directions.

The magnetic field signature of a $500-\mathrm{km}$ diameter crater emplaced above the magnetic paleopole is computed at an altitude of $400 \mathrm{~km}$. Results are shown in Fig. 4. The maximum thickness (i.e., $60 \mathrm{~km}$ ) is equivalent to the extreme curves in Fig. 3. When emplaced in a 4-km thick radially magnetized layer, a $500-\mathrm{km}$ diameter crater produces a $1.3 \mathrm{nT}$ magnetic anomaly with the maximum magnetic field located above the crater center. The magnetic field increases to 5.8 and $9.0 \mathrm{nT}$ for $20-\mathrm{km}$ and $40-\mathrm{km}$ thick layers, respectively. The peak is narrower for the radial field than for the total field, but the area over which the magnetic field is appreciable is larger than the cratered area.

[Fig. 4 somewhere here]

The magnetic field is smaller in amplitude when the pre-impact magnetization is horizontal (above the equator) and two extrema are present. These are shifted with respect to the crater center, as it is observed for increasing crater diameters with constant thicknesses (see Fig. 3). When the initial thickness is $4 \mathrm{~km}$, there is a $0.04 \mathrm{nT}$ difference between the maximum $(0.7 \mathrm{nT})$ field intensity and the field above the crater center. This difference increases to $0.1 \mathrm{nT}$ when the thickness exceeds $20 \mathrm{~km}$. Extrema are located inside the impact crater rim, but are separated by a few degrees. The difference between the maximum field and the field above the crater center represents $4 \%$ of the magnetic field signal for a 500-km diameter crater.

The thickness of the pre-impact magnetic layer not only affects the amplitude of the signal, but also its shape, especially for a horizontal magnetization. For very thin magnetized layers, the magnetic field presents a clear two-peak shape. The larger the crater is, the more pronounced this shape is. 


\subsection{Forward approach summary - The case of very large impact basins}

Our forward approach is focused on craters with diameters ranging between 100 and $500 \mathrm{~km}$. From a qualitative point of view, it may first be concluded that the magnetic field anomalies we computed are not located above the most magnetized areas: instead, they are centered above the magnetization contrasts that are created by the impact excavation. Based on our computations, the magnetic field above a crater of known diameter can be associated with a distinct shape and amplitude. These depend on the pre-impact magnetization direction and on the thickness of the magnetized layer, as can be seen when comparing Figs. 2 and 4. It is worth mentioning that the normalized approach chosen here allows an easy scaling to thicker or thinner pre-impact magnetized layer, as well as to larger magnetization values.

The second qualitative conclusion is expected from the theoretical point of view, but is less intuitive from the observations. Assuming the Martian lithosphere acquired its (pre-impact) magnetization in the presence of a dipolar and centered magnetic field, then demagnetized impacts are associated with maxima of the magnetic field intensity. This counterintuitive result is explained by the simple magnetization scheme we assumed. To a first order, a hole in a magnetized plate (i.e., an excavated impact crater) produces the same field as an isolated dipole located at the center of the hole, with its magnetic moment equal to the magnetized volume removed. This approximation is valid provided that the vertical distance to the source is much larger than the horizontal extend of the source, i.e. for the smaller diameters considered in our study. We go one step further, and we compute the magnetic field over a very large crater, 2000-km in diameter, assuming a radial or horizontal pre-impact 
magnetization and an initial thickness of $20 \mathrm{~km}$. At 400- (200-) km altitude, field extrema are equal to 16.91 (33.86) and 14.17 (17.16) nT above the rim and the crater center above the pole, and decrease to 6.21 (14.81) and 1.76 (1.43) nT above the equator. In this latter case, the field maxima is observed outside the impact crater. The signature above the rim is much more enhanced with respect to the field above the crater center at lower altitudes.

\section{Comparison with Observations}

MGS magnetic field measurements are associated with a measurement error of the order on $1 \mathrm{nT}$ (Acuña, 2003). Figs. 2 and 4 and the subsequent discussions suggest that the intensity anomaly associated with an impact crater will start dropping into this noise level for crater diameters smaller than about $200 \mathrm{~km}$. We now tackle the inverse problem and consider true measurements to estimate magnetic intensities above Mars impact craters. We restrict our study to well-recognized impact craters larger than $100 \mathrm{~km}$ in diameter. This database derives from the ones published by Barlow (1988) and by Tanaka et al. (1992), updated with more recent diameter estimates given by Schultz and Frey (1990); Frey et al. (1999); Frey (2006). We also consider large visible basins such as Hellas or Argyre. Overall our database consists of 260 impact craters or basins larger than $100 \mathrm{~km}$ in diameter. Their locations are shown in Fig. 5.

[Fig. 5 somewhere here]

There are two main difficulties when investigating the internal crustal field of Mars (or of any other planet) from real magnetic field measurements. The 
first one arises because of rapid temporal fluctuations (associated with external fields). The second one is related to the spatial resolution of magnetic field measurements, which depends on both spacecraft altitude and orbit as well as on the horizontal spatial wavelength of the Martian magnetic field.

The first issue may be circumvented by considering a rather large number of measurements spanning long time intervals. Indeed periodic or transient time varying signals tend to cancel out. Other magnetic field temporal variations caused by magnetic sources closer to the spacecraft altitudes can be further minimized through potential field modeling methods. These methods, in turn, generally provide a means to predict the magnetic field at lower altitudes and enhance the spatial resolution of the field. Two important quantities are also estimated, the measurement error and its geographical distribution, and the minimum horizontal spatial dimension detectable from the distribution of sparse measurements.

We first determine the robustness of MGS observations over the impact craters with the help of three independent modeling approaches. We perform the first analysis with a spherical harmonic ( $\mathrm{SH}$ ) model of the Martian magnetic field. The model of Cain et al. (2003) is based on MGS AeroBraking (AB), Science Phase Orbit (SPO) and Mapping Orbit (MO) measurements acquired until March 2000, and expands up to SH degree $n$ and order $m$ 90. Cain et al. (2003) pointed out that most of the power is contained by terms ranging between $n$ $=15$ and $n=40$. However all terms are collectively needed to represent the small spatial scales. We therefore use the untruncated model. We choose to not downward continue this model to the Martian surface, as the noise would considerably be enhanced. The magnetic field is computed above each crater of our database for altitudes equal to $200 \mathrm{~km}, 250 \mathrm{~km}, 300 \mathrm{~km}, 350 \mathrm{~km}$ and 
$400 \mathrm{~km}$, from which we derive the mean magnetic field intensity. The results are shown in Fig. 6a. The SH model of Cain et al. (2003) has an estimated horizontal length scale of about $230 \mathrm{~km}$, as deduced from the simple formula $\lambda \simeq 2 \pi R_{M} / n$ (Backus et al., 1996, p. 101), with $R_{M}$, the mean Martian radius, equal to $3393.5 \mathrm{~km}$. Thus, field estimates deriving from the $\mathrm{SH}$ representation of the magnetic field for craters smaller than $230 \mathrm{~km}$ diameter may be biased.

The ESD model of Langlais et al. (2004) offers an independent way to estimate the mean magnetic field above the same craters. This model is based on a different set of MGS AB, SPO and MO measurements. This approach is less sensitive to data gaps (Langel and Hinze, 1998). The horizontal distance between adjacent dipoles is $173 \mathrm{~km}$. When transformed into and compared to other SH models, associated magnetic energy spectra do correlate well up to $n=50$ (Whaler and Purucker, 2005). Higher degree terms of SH models possibly contain some noise. Mean magnetic field intensities computed with the ESD model are shown in Fig. 6b.

[Fig. 6 somewhere here]

The SH and ESD predictions compare visually well at measurement altitude for craters larger than $200 \mathrm{~km}$. The correlation between these two series of magnetic field intensities is larger than 0.99 , with a root mean square difference (rms) between the two series equal to $1.6 \mathrm{nT}$ and $5.5 \mathrm{nT}$ at $400-\mathrm{km}$ and 200$\mathrm{km}$ altitude, respectively. These differences are on the order of the combined estimated measurement noise and external field contributions (Langlais et al., 2004). These have to be compared to the rms field above the craters of our database, which is equal to $13.0 \mathrm{nT}$ and $34.8 \mathrm{nT}$ at the same two altitudes, respectively. The field $B$ vs. crater diameter $D$ distribution is very scattered 
for craters smaller than $200 \mathrm{~km}$, but similar correlation coefficients and slightly larger rms differences between the two modeling approaches are observed.

A third analysis is performed in order to confirm that the obtained mean intensity values are independent of global data modeling methods. We use a regional modeling strategy and apply the Revised Spherical Cap Harmonic Analysis (R-SCHA, Thébault et al., 2006) to process MGS data above impact craters. The general setting of the inversion procedure is detailed in Thébault (2006) and references therein. The objective of this approach is to find an independent solution for the magnetic field above each considered crater. Local R-SCHA basis functions are set to solve the inverse problem by minimizing least-squares residuals with a theoretical horizontal spatial resolution of 100 $\mathrm{km}$. Regional magnetic field models are derived from MGS MO measurements acquired during the two last years of the mission, 2005 and 2006, during which the solar activity was close to its minimum. A limitation of the R-SCHA technique is that the downward continuation is not stable when low altitude or ground based measurements are not available. For this reason, we choose to restrict our calculations to a unique altitude of $400 \mathrm{~km}$, which is the average altitude of the MGS data during its mapping phase. This approach also provides us with a local estimate of the signal-to-noise ratio above each considered crater. The availability of local statistics offers an appreciable advantage over global models for which this information is not locally available.

[Fig. 7 somewhere here]

These independent estimates are shown in Fig. 7. The new results agree well with those based on the global ESD and SH models. Despite the theoretical horizontal spatial resolution of $100 \mathrm{~km}$, the scatter associated with the mean 
magnetic field intensity dramatically increases again for craters smaller than $200 \mathrm{~km}$. The standard deviations obtained for each local inversion indicate that the signal is not equally constrained over all craters. Intensity errors range between $1.8 \mathrm{nT}$ and $10.8 \mathrm{nT}$, with an average value of $4.1 \mathrm{nT}$. This compares well with the rms difference computed between the SH and the ESD models. Error bars associated with the R-SCHA modeling approach are shown in Fig. 7, together with the 400-km altitude estimates based on SH and ESD models. They all lie within the independent error bars of the new intensity estimates. For all craters the local (R-SCHA) and the global (ESD and SH) models correlate at more than $99 \%$, with rms differences on the order of 3.5 nT.

\section{Discussion on the magnetic characterization of impact craters}

We first note from Fig. 6 and 7 that large craters can be associated with large magnetic fields and smaller craters with low ones. We observe that there exists a resolution cutoff at $200 \mathrm{~km}$ in the magnetic models. This apparent threshold, which agrees well with the forward modeling conclusions, is a good starting point to investigate whether impact crater diameters and magnetic field intensity are correlated or anti-correlated.

We look for a linear relationship between these quantities for craters larger than 200 km. Least-squares regressions (Fig. 6) for SH estimates show a negative slope of $-5.110^{-3} \mathrm{nT} \cdot \mathrm{km}^{-1}$ and $-13.610^{-3} \mathrm{nT} \cdot \mathrm{km}^{-1}$ at altitudes of $400 \mathrm{~km}$ and $200 \mathrm{~km}$, respectively. ESD-based regressions show similar slopes, $-5.010^{-3}$ $\mathrm{nT} \cdot \mathrm{km}^{-1}$ and $-13.6 \mathrm{nT} \cdot \mathrm{km}^{-1}$, respectively. At 400-km altitude however, the 95\%-confidence interval contains the zero-slope. Taking advantage of the inde- 
pendent error estimates associated with each crater derived from the regional modeling formalism, we also perform a weighted least-squares regression to obtain more robust values at $400-\mathrm{km}$ altitude using the R-SCHA results. The new result is comparable, with a slope equal to $-4.710^{-3} \mathrm{nT} \cdot \mathrm{km}^{-1}$ (red curve in Fig.7). This corresponds to a weighted correlation coefficient of -0.23 .

However, these statistical analyzes may be limited by the rather low number of craters: only 55 craters have diameters larger than $200 \mathrm{~km}$, and the estimated correlation coefficient may be biased by this small amount of samples. This problem is illustrated in Fig. 7. We carry out two Bayesian inversions to estimate the true confidence interval of the slope of the unweighted leastsquares regression. The algorithm uses either a least-squares or a least-absolute deviation measure of misfit. We further investigate the validity of the result by iteratively removing only one data point in the calculation of the slope (not shown). The least-squares approach is less robust than the least-absolute deviation one because some craters bias the result of the regression towards negative slopes. These five craters have diameters between 200 and $600 \mathrm{~km}$, and are associated with larger magnetic fields than the other impact craters of similar dimensions (see the five points well above the curve in Fig. 7). The stable least-absolute deviation Bayesian inversion gives a maximum likelihood slope around $-4.310^{-3} \mathrm{nT} \cdot \mathrm{km}^{-1}$, a value slightly lower than that found in the least-squares sense. This leads to a new, apparently more robust, correlation coefficient estimate of -0.16 .

Other sources of uncertainty may lead to errors in determining the correlation coefficient and we now try to estimate its error bar. Exploring the full space of parameters affecting the estimates of the correlation coefficient is troublesome but we identify at least two factors that can be easily controlled. First, the 
value of the estimated correlation coefficient may be sensitive to the choice of the apparent resolution limit of $200-\mathrm{km}$. This lower boundary is an approximation that may not be accurate everywhere on Mars because the strength of the magnetic field may fall within the noise level due to the relatively high altitude of the measurements. Second, the data error, which is not equal for all craters, may play a significant role and must be studied for evaluating the uncertainty of the correlation coefficient.

[Fig. 8 somewhere here]

We first test the $200-\mathrm{km}$ limit by increasing the lower bound of our crater database, from $200 \mathrm{~km}$ to $500 \mathrm{~km}$ with a 10-km increment. We find that the minimum correlation coefficient is -0.33 for a lower boundary equal to 280 $\mathrm{km}$, the maximum value being -0.07 . Keeping $200 \mathrm{~km}$ as a lower boundary, we add different random noises to the mean magnetic field estimated at $400-\mathrm{km}$ altitude above each crater using the standard deviations given by the regional models. The correlation coefficients are then distributed within the interval [-0.40 -0.05]. We conclude that the magnetic error over impact craters is particularly detrimental to a robust estimate of the correlation coefficient between intensity and impact craters. Yet, the correlation coefficient is still confirmed to differ significantly from zero. We complete these tests by computing the correlation coefficients for random distributions of impact craters on the surface of Mars. 40,000 random distributions are generated, with 55 craters whose diameters larger than $200 \mathrm{~km}$ correspond to those of the database. We are careful to create the crater locations with a pseudo-random generator that uniformly distributes the points over the surface of the sphere. The distribution of correlation coefficients is shown in Fig. 8. The actual result lies, of course, within the distribution but a major conclusion is that the interval of 
possible values calculated from noisy data in the real case (i.e., [-0.40 -0.05]) covers a wide range of correlations obtained by the random distribution. From all statistical tests carried out above, including the zero-slope between crater diameter and mean magnetic signal contained in the $95 \%$ confidence interval at $400 \mathrm{~km}$, we conclude that the maximum likelihoods for the correlation number are systematically negative but, according to the shape of the histogram, we do not rule out that the estimated anti-correlation between the mean magnetic intensity and crater diameter is fortuitous and due to the low number of available craters with dimension larger than 200-km.

\section{Summary}

In this study, we simulate and present the magnetic field signatures of impact craters at a constant altitude of $400 \mathrm{~km}$ above the surface. Our computations are based on reasonable assumptions on the pre-impact Martian magnetization for a large range of crater diameters. In our very simple scheme, magnetic anomalies are not necessarily collocated with magnetized areas; instead, they are collocated with magnetization anomalies. These magnetization anomalies are the holes made by the impacts within the magnetized lithosphere. Unlike the gravity field, which would exhibit a regional low above an uncompensated impact crater, a deficit of magnetization is theoretically not expected to produce a deficit of, or a low magnetic field intensity; instead it can locally create an excess of magnetic field. We show that the crater diameter, the pre-impact magnetization direction, and the thickness of the magnetized layer do influence the magnetic field signature of these craters. Under conservative assumptions for the demagnetization, a 200-km impact crater emplaced within a $1 \mathrm{~A} / \mathrm{m}$ 
magnetized lithosphere may be associated with a magnetic field signature on the order of $1 \mathrm{nT}$ at 400-km altitude. The craters we considered in our forward modeling approach are not large enough to create strong magnetic fields on their rims with weaker magnetic field in their centers at spacecraft altitudes. However, larger depth-to-diameter ratios, either because the pre-impact magnetized layer is thinner, or because the demagnetized depth is larger, are likely to produce such ring-like magnetic structures.

While most Martian craters show a magnetic minimum inside their rims, the morphology of the surrounding magnetic field is much more complicated than a simple annulus (as predicted above the pole), or than a two-lobe structure (as predicted above the equator). The southern area of Hellas is devoid of significant magnetic field, while the northern rim has some. Similar features are observed above other craters. Recent magnetic field maps show small extremas close to the crater centers of Utopia and Argyre (Lillis et al., 2010). To be more realistic one would have to take into account the superposition of impact craters which successively shaped the Martian lithosphere, making it much more complex than a spherical shell with isolated holes. A forward modeling approach taking into account all these successive impacts is however hardly conceivable, because it would require the exact knowledge of the timeline of craters, volcanoes, and other events which affected Mars' upper layers, by demagnetizing and possibly remagnetizing it locally. Nonetheless, our approach sets limits on the magnetic signature of large Martian impact craters and enables characterizing their possible demagnetization (or absence of demagnetization) using orbital measurements.

We also perform a statistical analysis of Martian impact craters and their measured magnetic signatures at 400-km altitude, for crater diameters ranging 
between $100 \mathrm{~km}$ and more than $2000 \mathrm{~km}$. Our computations are based on existing magnetic field (Cain et al., 2003) and magnetization (Langlais et al., 2004) models, as well as on more recent data. Two distinct patterns are worth noting. First, the results based on the three different input datasets agree remarkably well with the intensity above impact craters larger than 200-km diameter, and less for smaller diameters. Second, large craters (i.e., > $200 \mathrm{~km}$ ) display a gross negative correlation between diameter and mean magnetic field, with a correlation coefficient of -0.23 . Statistical tests, however, demonstrate that this correlation coefficient may be fortuitous. At 400-km altitude, the mean magnetic field intensity associated with impact craters ranges between 3.2 and $69.9 \mathrm{nT}$. In contrast, the signature of smaller craters is much more scattered. At 400-km altitude, their magnetic field signatures vary from 2.1 to $161.8 \mathrm{nT}$, and may reflect more the magnetic pattern of their immediate surroundings than the demagnetized area itself. An alternative explanation is that some craters were emplaced while the dynamo was still active, thus they may be associated with remagnetization patterns.

Our conclusions are not surprising both from an observational and theoretical point of view. First, we considered data noise in our calculation of correlation coefficients, but many fundamental sources of uncertainties should also be taken into account. Characterizing crater diameters is under strong debate, as illustrated by the sometimes divergent crater databases (see Section 4). Large craters have multiple rims and it is sometimes difficult to identify the main one. We established our crater database using the most consensual definition we could find in the literature. However, even in this case, crater diameter values are found to vary from one study to another depending on available observations and retained criteria. For example the Sirenum impact basin is 
associated with a diameter of $460 \mathrm{~km}$ following Barlow (1988), but Frey (2006) reported a much larger size of $1069 \mathrm{~km}$. An estimate of the error associated with crater diameter would be informative and would help in assessing more robust statistics between crater diameter and magnetic field intensity.

The main limitation for a statistical analysis is the relatively low number of available craters. Only the magnetic field signature of craters larger than 200 $\mathrm{km}$ can be considered reliable. This minimum size is actually related to the horizontal resolution of the available measurements or models of the Martian magnetic field. But this 200-km diameter threshold is very interesting if one assumes that the considered impact craters postdate the shutdown of the Martian dynamo. In this case impact craters larger than $200 \mathrm{~km}$ in diameter may have demagnetized the pre-impact magnetized crust over its entire depth. Deep-seated remanent magnetization would still be present in some areas, while the crust would be entirely demagnetized in other regions. Considering a 0.1 depth-to-diameter ratio for the demagnetization, the apparent cutoff around $200 \mathrm{~km}$ indicates that the magnetic crust of Mars cannot be thinner than $20 \mathrm{~km}$ on average. Of course, this is a putative interpretation, since it is likely that some craters were emplaced before the cessation of the dynamo. Very likely, some craters of our database are demagnetized, while some other are not. This might explain why no clear and unambiguous relationship can be globally established between impact craters and magnetic field anomalies, even if the magnetic field signal above craters larger than $200 \mathrm{~km}$ in diameter is robust.

[Fig. 9 somewhere here]

The MGS mission provided very valuable measurements of the magnetic field. 
Multiple and complete coverages were acquired at a quasi-constant altitude of $400 \mathrm{~km}$, while sparse measurements were acquired below, down to about $90 \mathrm{~km}$. Complementary indirect measurements of the magnetic field intensity were also acquired, thanks to the ER experiment (Lillis et al., 2008b). Measurement altitude and accuracy are important parameters, as they define the smallest crater visible from a magnetic point of view. We present in Fig. 9 the maximum magnetic field intensity associated with a demagnetized impact crater as a function of the measurement altitude (from 50 to $500 \mathrm{~km}$ ) and the crater diameter at the magnetic pole and at the magnetic equator. A 200-km altitude and below, the magnetic signal is larger: a 200-km diameter crater has a magnetic field anomaly ranging between $2.9 \mathrm{nT}$ and $5.7 \mathrm{nT}$. A 100-km diameter crater may be associated with a magnetic field signature between 0.5 $\mathrm{nT}$ and $0.9 \mathrm{nT}$ depending on the pre-impact magnetization directions. These larger signatures should in principle facilitate their magnetic characterization. There are only 55 craters larger than $200 \mathrm{~km}$ in the database we used in our study, but there are 260 craters larger than $100 \mathrm{~km}$. Provided that the horizontal resolution of the Martian lithospheric magnetic field can be increased, it should be possible to estimate more accurately which impact craters are indeed not magnetized and which ones are still.

The dynamo cessation had drastic consequences on the Martian planetary enyironment (Chassefière et al., 2007) and on the evolution of its surface (Bibring et al., 2006; Mustard et al., 2009), by constraining the fate of water on Mars (Sprenke and Baker, 2003; Tosca and Knoll, 2009). Accurate determination of the timing of the dynamo shutdown is therefore crucial for understanding internal and surface processes throughout the history of Mars. This is another strong argument for sending a future scientific spacecraft to Mars, 
on a relatively low orbit, to provide a complete survey of the lithospheric Martian magnetic field at altitudes ranging between 150 and $200 \mathrm{~km}$. Such a mission was proposed to ESA, to jointly study Mars' magnetic field and atmosphere (Leblanc et al., 2009; Langlais et al., 2009). Recently, the Mars Atmosphere and Volatile Evolution (MAVEN) mission to Mars was selected by NASA (Jakosky, 2009). These low-altitude magnetic field measurements will allow the magnetic signature associated with craters as small as $100 \mathrm{~km}$ to be characterized. By comparing these magnetic signatures to the relative (and possibly absolute) chronology of these craters, we would be able to estimate the timeline of the Martian dynamo on Mars, and in particular, when it died and if this cessation was related to giant impacts as suggested by Roberts et al. (2009) or to internal processes such as decrease in the CMB heat flux as proposed by Kuang et al. (2008).

\section{acknowledgments}

This study was supported by Agence Nationale de la Recherche (project ANR08-JCJC-0126-01) and by PNP/INSU. We wish to thank three anonymous reviewers for their insightful reviews which helped us to improve the quality of our manuscript. For IPGP this is number XXXX.

\section{References}

M. H. Acuña. The Magnetic Field of Mars. The Leading Edge, 22:769-771, 2003.

M. H. Acuña, J. E. P. Connerney, N. F. Ness, R. P. Lin, D. Mitchell, C. W. 
Carlson, J. McFadden, K. A. Anderson, H. Reme, C. Mazelle, D. Vignes, P. Wasilewski, and P. Cloutier. Global Distribution of Crustal Magnetization Discovered by the Mars Global Surveyor MAG/ER Experiment. Science, 284, 1999.

M. H. Acuña, J. E. P. Connerney, P. Wasilewski, R. P. Lin, K. A. Anderson, C. W. Carlson, J. McFadden, D. W. Curtis, D. Mitchell, H. Reme, C. Mazelle, J. A. Sauvaud, C. D'Uston, A. Cros, J. L. Medale, S. J. Bauer, P. Cloutier, M. Mayhew, D. Winterhalter, and N. F. Ness. Magnetic Field and Plasma Observations at Mars: Initial Results of Mars Global Surveyor mission. Science, 279, 1998.

J. Arkani-Hamed. Paleomagnetic pole positions and pole reversals of Mars. Geophys. Res. Lett., 28, 2001.

N. Artemieva, L. L. Hood, and B. A. Ivanoy. Impact demagnetization of the Martian crust: Primaries versus secondaries. Geophys. Res. Lett., 32, 2005.

G. Backus, R. Parker, and C. Constable. Foundations of Geomagnetism. Cambridge University Press, Cambridge, UK, 1996.

N. G. Barlow. Crater size/frequency distributions and a revised relative Martian chronology. Icarus, 75:285-305, 1988.

N. G. Barlow, R. A. Allen, and F. Vilas. Mercurian impact craters: implications for polar ground ice. Icarus, 141:194-204, 1999.

J.-P. Bibring, Y. Langevin, J. F. Mustard, F. Poulet, R. E. Arvidson, A. Gendrin, B. Gondet, N. Mangold, P. Pinet, and F. Forget. Global mineralogical and aqueous Mars history derived from OMEGA/Mars Express data. Science, 312:400-404, 2006.

D. Boutin and J. Arkani-Hamed. Pole wandering of Mars: evidence from paleomagnetic poles. Icarus, 181, 2006.

J. C. Cain, B. B. Ferguson, and D. Mozzoni. An $\mathrm{n}=90$ internal potential 
function of the Martian crustal magnetic field. J. Geophys. Res., 108, 2003.

E. Chassefière, F. Leblanc, and B. Langlais. The combined effects of escape and magnetic field histories at Mars. Planet. Space Sci., 55, 2007.

J. E. P. Connerney, M. H. Acuña, P. J. Wasilewski, N. F. Ness, H. Reme, C. Mazelle, D. Vignes, R. P. Lin, D. L. Mitchell, and P. A. Cloutier. Magnetic lineations in the ancient crust of Mars. Science, 284:794-+, 1999.

S. K. Croft. The excavation stage of basin formation - a qualitative model. In R. B. Merill and P. H. Schultz, editors, Multi-ring basins: Formation and Evolution, pages 207-225, 1981.

S. K. Croft. The scaling of complex craters. J. Geophys. Res., 90:828-842, 1985.

J. J. Frawley and P. T. Taylor. Paleo-pole positions from martian magnetic anomaly data. Icarus, 172:316-327, 2004.

H. Frey, S. E. H. Sakimoto, and J. H. Roark. Discovery of a $450 \mathrm{~km}$ diameter, multi-ring basin on Mars through analysis of MOLA topographic data. Geophys. Res. Lett., 26:1657-1660, 1999.

H. V. Frey. Impact constraints on, and a chronology for, major events in early Mars history. J. Geophys. Res., 111, 2006.

H. V. Frey. Ages of very large impact basins on Mars: Implications for the late heavy bombardment in the inner solar system. Geophys. Res. Lett., 2008.

J. B. Garvin and J. J. Frawley. Geometric properties of Martian impact craters: Preliminary results from the Mars Orbiter Laser Altimeter. Geophys. Res. Lett., 25:4405-4408, 1998.

R. A. F. Grieve, P. B. Robertson, and M. R. Dence. Constraints on the formation of ring impact structures, based on terrestrial data. In R. B. Merill and P. H. Schultz, editors, Multi-ring basins: Formation and Evolution, pages 37-57, 1981. 
D. J. Heather and S. K. Dunkin. Geology and stratigraphy of King crater, lunar farside. Icarus, 163, 2003.

L. L. Hood, K. P. Harrison, B. Langlais, R. J. Lillis, F. Poulet, and D. A. Williams. Magnetic anomalies near Apollinaris Patera and the Medusae Fossae formation in Lucus Planum, Mars. Icarus, xx, 2010.

L. L. Hood, N. C. Richmond, E. Pierazzo, and P. Rochette. Distribution of crustal magnetic fields on Mars: Shock effects of basin-forming impacts. Geophys. Res. Lett., 30, 2003.

L. L. Hood, C. N. Young, N. C. Richmond, and K. P. Harrison. Modeling of major martian magnetic anomalies: Further evidence for polar reorientations during the Noachian. Icarus, 177, 2005.

B. M. Jakosky. The 2013 Mars Atmosphere and Volatile Evolution (MAVEN) Mission to Mars. AGU Fall Meeting Abstracts, 2009.

A. Katanforoush and M. Shahshahani. Distributing Points on the Sphere, I. Exp. Math., 12:199-209, 2003.

W. Kuang, W. Jiang, and T. Wang. Sudden termination of Martian dynamo?: Implications from subcritical dynamo simulations. Geophys. Res. Lett., 35, 2008.

R. A. Langel and W. J. Hinze. The Magnetic Field of the Earth's Lithosphere. Cambridge University Press, Cambridge, UK, 1998.

B. Langlais, F. Leblanc, T. Fouchet, S. Barabash, D. Breuer, E. Chassefière, A. Coates, V. Dehant, F. Forget, H. Lammer, S. Lewis, M. Lopez-Valverde, M. Mandea, M. Menvielle, A. Pais, M. Paetzold, P. Read, C. Sotin, P. Tarits, S. Vennerstrom, G. Branduardi-Raymont, G. Cremonese, J. G. M. Merayo, T. Ott, H. Rème, J. G. Trotignon, and J. E. Walhund. Mars Environment and Magnetic Orbiter: model payload. Exp. Astron., 22, 2009.

B. Langlais, V. Lesur, M. E. Purucker, J. E. P. Connerney, and M. Mandea. 
Crustal Magnetic Fields of Terrestrial Planets. Space Sci. Rev., 152, 2010.

B. Langlais and M. E. Purucker. A polar magnetic paleopole associated with Apollinaris Patera. Planet. Space Sci., 55, 2007.

B. Langlais, M. E. Purucker, and M. Mandea. Crustal magnetic field of Mars. J. Geophys. Res., 109, 2004.

F. Leblanc, B. Langlais, T. Fouchet, S. Barabash, D. Breuer, E. Chassefière, A. Coates, V. Dehant, F. Forget, H. Lammer, S. Lewis, M. Lopez-Valverde, M. Mandea, M. Menvielle, A. Pais, M. Paetzold, P. Read, C. Sotin, P. Tarits, and S. Vennerstrom. Mars Environment and Magnetic Orbiter: Science and Measurement Objectives. Astrobiology, 2009.

R. J. Lillis, H. V. Frey, and M. Manga. Rapid decrease in Martian crustal magnetization in the Noachian era: Implications for the dynamo and climate of early Mars. Geophys. Res. Lett., 35, 2008a.

R. J. Lillis, H. V. Frey, M. Manga, D. L. Mitchell, R. P. Lin, M. H. Acuña, and S. W. Bougher. An improved crustal magnetic field map of Mars from electron reflectometry: Highland volcano magmatic history and the end of the martian dynamo. Icarus, 194, 2008b.

R. J. Lillis, M. Manga, D. L. Mitchell, R. P. Lin, and M. H. Acuña. Unusual magnetic signature of the Hadriaca Patera Volcano: Implications for early Mars. Geophys. Res. Lett., 33, 2006.

R. J. Lillis, M. E. Purucker, J. S. Halekas, K. L. Louzada, S. T. StewartMukhopadhyay, M. Manga, and H. V. Frey. Study of impact demagnetization at mars using monte carlo modeling and multiple altitude data. $J$. Geophys. Res., 115, 2010.

P. J. McGovern, J. R. Smith, J. K. Morgan, and M. H. Bulmer. Olympus Mons aureole deposits: New evidence for a flank failure origin. J. Geophys. Res., 109, 2004a. 
P. J. McGovern, S. C. Solomon, D. E. Smith, M. T. Zuber, M. Simons, M. A. Wieczorek, R. J. Phillips, G. A. Neumann, O. Aharonson, and J. W. Head. Correction to "Localized gravity/topography admittance and correlation spectra on Mars: Implications for regional and global evolution". J. Geophys. Res., 109, 2004b.

H. J. Melosh. Impact cratering: A geologic process. Oxford University Press, New York, 1989.

C. A. E. Milbury and G. Schubert. Search for the global signature of the Martian dynamo. J. Geophys. Res., 115, 2010.

P. S. Mohit and J. Arkani-Hamed. Impact demagnetization of the martian crust. Icarus, 168, 2004.

J. F. Mustard, B. L. Ehlmann, S. L. Murchie, F. Poulet, N. Mangold, J. W. Head, J.-P. Bibring, and L. H. Roach. Composition, Morphology, and Stratigraphy of Noachian Crust around the Isidis basin. J. Geophys. Res., $114,2009$.

F. Nimmo and M. S. Gilmore. Constraints on the depth of magnetized crust on Mars from impact craters. J. Geophys. Res., 106, 2001.

J. D. O'Keefe and T. J. Ahrens. Planetary cratering mechanics. J. Geophys. Res., 98:17011-17028, 1993.

R. L. Parker. Ideal bodies for Mars magnetics. J. Geophys. Res., 108, 2003.

L. V. Potts, R. R. von Frese, T. E. Leftwich, P. T. Taylor, C. K. Shum, and R. Li. Gravity-inferred crustal attributes of visible and buried impact basins on Mars. J. Geophys. Res., 109, 2004.

L. V. Potts and R. R. B. von Frese. Crustal attributes of lunar basins from terrain-correlated free-air gravity anomalies. J. Geophys. Res., 108, 2003.

M. E. Purucker, T. J. Sabaka, and R. A. Langel. Conjugate gradient analysis: A new tool for studying satellite magnetic data sets. Geophys. Res. Lett., 
23:507-510, 1996.

Y. Quesnel, B. Langlais, and C. Sotin. Local inversion of magnetic anomalies: Implication for Mars' crustal evolution. Planet. Space Sci., 55, 2007.

Y. Quesnel, C. Sotin, B. Langlais, S. Costin, M. Mandea, M. Gottschalk, and J. Dyment. Serpentinization of the martian crust during Noachian. Earth Planet. Sci. Lett., 277, 2009.

J. H. Roberts, R. J. Lillis, and M. Manga. Giant impact on early Mars and the cessation of the Martian dynamo. J. Geophys. Res., 114, 2009.

P. Rochette. Crustal magnetization of Mars controlled by lithology or cooling rate in a reversing dynamo? Geophys. Res. Lett., 33, 2006.

P. Rochette, G. Fillion, R. Ballou, F. Brunet, B. Ouladdiaf, and L. L. Hood. High pressure magnetic transition in pyrrhotite and impact demagnetization on Mars. Geophys. Res. Lett., 30, 2003.

S. K. Runcorn. On the interpretation of Lunar magnetism. Phys. Earth Planet. Int., 10:327-335, 1975.

R. A. Schultz and H. V. Frey. A new survey of multiring impact basins on Mars. J. Geophys. Res., 95:14175-14189, 1990.

H. Shahnas and J. Arkani-Hamed. Viscous and impact demagnetization of Martian crust. J. Geophys. Res., 112, 2007.

K. F. Sprenke and L. L. Baker. Exploring for water on Mars: The case for mapping the low-altitude magnetic field. J. Geophys. Res., 108, 2003.

K. L. Tanaka, D. H. Scott, and R. Greeley. Global stratigraphy, chapter 11, pages 345-382. Arizona Press, Tucson, AZ, H. H. Kieffer, B. J. Jakosky, C. W. Snyder, C. W., and M. S. Matthews, Eds., 1992.

E. Thébault. Global lithospheric magnetic field modelling by successive regional analysis. Earth Planets Space, 58:485-495, 2006.

E. Thébault, M. Purucker, K. A. Whaler, B. Langlais, and T. J. Sabaka. The 
Magnetic Field of the Earth's Lithosphere. Space Sci. Rev., 155, 2010.

E. Thébault, J. J. Schott, and M. Mandea. Revised Spherical Cap Harmonic Analysis (R-SCHA): Validation and Properties. J. Geophys. Res., 111, 2006.

P. C. Thomas, J. A. Burns, L. Rossier, D. Simonelli, J. Veverka, C. R. Chapman, K. Klaasen, T. V. Johnson, and M. J. S. Belton. The Small Inner Satellites of Jupiter. Icarus, 135:360-371, 1998.

N. J. Tosca and A. H. Knoll. Juvenile chemical sediments and the long term persistence of water at the surface of Mars. Earth Planet. Sci. Lett., 286, 2009.

B. P. Weiss, H. Vali, F. J. Baudenbacher, J. L. Kirschvink, S. T. Stewart, and D. L. Shuster. Records of an ancient Martian magnetic field in ALH84001. Earth Planet. Sci. Lett., 201, 2002.

S. C. Werner. The global martian volcanic evolutionary history. Icarus, 201, 2009.

K. A. Whaler and M. E. Purucker. A spatially continuous magnetization model for Mars. J. Geophys. Res., 110, 2005.

M. A. Wieczorek and R. J. Phillips. Lunar Multiring Basins and the Cratering Process. Icarus, 139:246-259, 1999. 
Fig. 1. Estimated and observed depth-to-diameter ratios for various craters: [red] pluses and [black] crosses correspond to lunar nearside and farside craters (Potts and von Frese, 2003); filled [black] circles (with error bars) are those associated with lunar multiring craters (Wieczorek and Phillips, 1999). The [blue] star corresponds to the King crater on the Moon (Heather and Dunkin, 2003), while open [purple] squares correspond to craters of the inner satellites of Jupiter (Thomas et al., 1998). The gray area denotes the 0.1 depth-to-diameter ratio retained in this study.

Fig. 2. Predicted magnetic field signature (top: radial field; bottom: total field) at 400-km altitude, for a $200-\mathrm{km}$ wide impact crater (rim shown by the white circle) above the magnetic pole (left) and the equator (right).

Fig. 3. Predicted magnetic field signature at 400-km altitude along a north-south profile, centered above crater centers with increasing diameters. Total (top panels) and radial (bottom panels) field are shown, for vertical (left column) or horizontal (right column) magnetization ( $C 1$ and $C_{4}$ cases respectively). Lateral extension of 100-, 250- and 500-km diameter craters is shown with arrows. For case $C 1(C 4)$, only curves associated with craters larger than $200 \mathrm{~km}(250 \mathrm{~km})$ are labeled; smaller crater signatures are indiscernible. 
Fig. 4. Predicted magnetic field signature at 400-km altitude along north-south profiles centered above craters with increasing pre-impact magnetized layer thickness (step is $4 \mathrm{~km}$ ). Total (top panels) and radial (bottom panels) field are shown, for vertical (left) or horizontal (right) magnetization $C 1$ and $C 4$ cases). Lateral extent of a $500-\mathrm{km}$ diameter crater is shown. For case $C 1(C 4)$, only curves associated with thicknesses smaller than 28 (20) km are labeled. Curves are not discernible for thickness equal to 48 and $52 \mathrm{~km}$, and strictly overlap for larger thicknesses.

Fig. 5. Rim location of the 260 impact basins with diameter larger than $100 \mathrm{~km}$.

Fig. 6. Mean magnetic field estimated above craters larger than $100 \mathrm{~km}$, at different altitudes: $200 \mathrm{~km}$ ([red] diamonds), $250 \mathrm{~km}$ ([orange] circles), $300 \mathrm{~km}$ ([green] triangles), $350 \mathrm{~km}$ ([blue] stars, and $400 \mathrm{~km}$ ([black] inverted triangles). Top panel shows SH-based estimates (Cain et al., 2003), while bottom panel shows ESD-based estimates (Langlais et al., 2004). In each panel, the linear regression line between mean magnetic field at 400-km (200-km) altitude and craters larger than $200 \mathrm{~km}$ is shown in black (red) together with the $95 \%$ confidence interval (gray area).

Fig. 7. Mean magnetic field estimated at $400 \mathrm{~km}$ altitude above craters larger than $100 \mathrm{~km}$. Red diamonds and error bars are based on regional modeling approach, while blue circles and green triangles are based on SH and ESD models. Red line shows the linear regression in the least-squares sense between weighted intensities and crater diameters, while the gray shading area is the probability distribution of the linear regression obtained with a least-absolute deviation Bayesian inversion. 
Fig. 8. Distribution histogram of correlation coefficients between crater diameter and magnetic field intensity mean value above each crater. The same crater diameter database is used 40, 000 times to randomly place craters at the surface of Mars. Cumulative Distribution Function is also shown [black curve], as well as the true correlation coefficient [star] and interval of possible correlation (red bar on the abscissa - see text for details).

Fig. 9. Predicted maximum magnetic field at different altitudes for a radial (left) and a horizontal (right) magnetization. Mean initial magnetization is $1 \mathrm{~A} \cdot \mathrm{m}^{-1}$, and it is assumed that the pre-impact magnetizatio thickness exceeds the crater excavation depth. Labels on the right side of each curve denote crater diameters, from 50 to $500 \mathrm{~km}$. For instance, a 300-km diameter crater with a pre-impact radial magnetization will be associated with a maximum magnetic signal equal to $4 \mathrm{nT}$ at $350-\mathrm{km}$ altitude. 


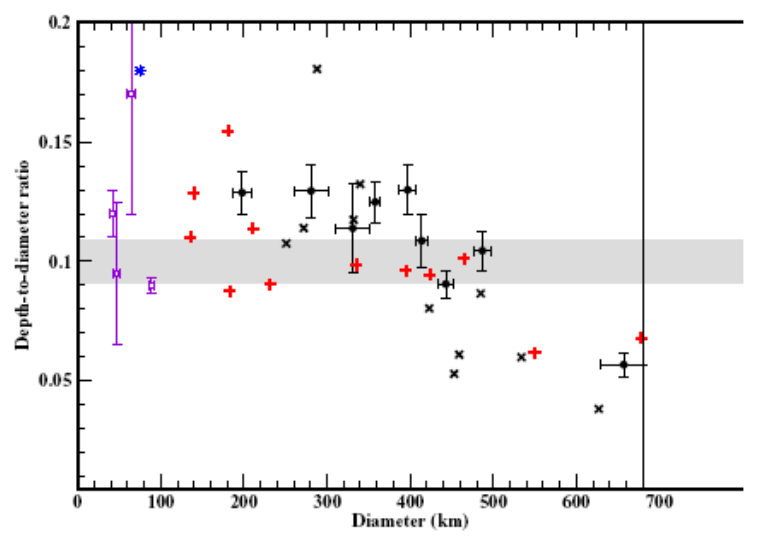




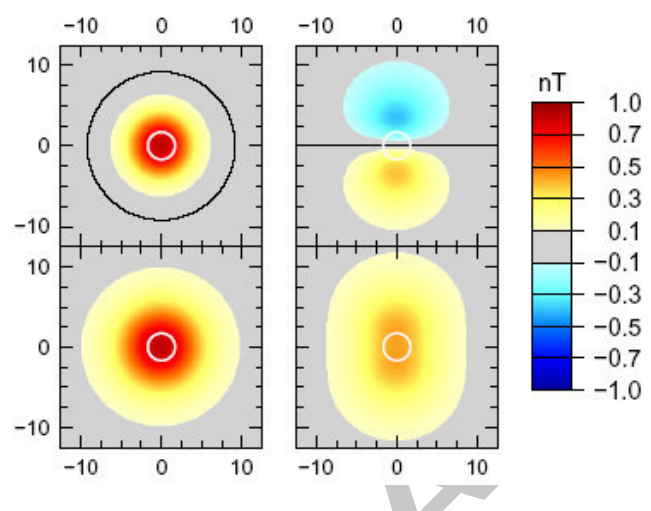




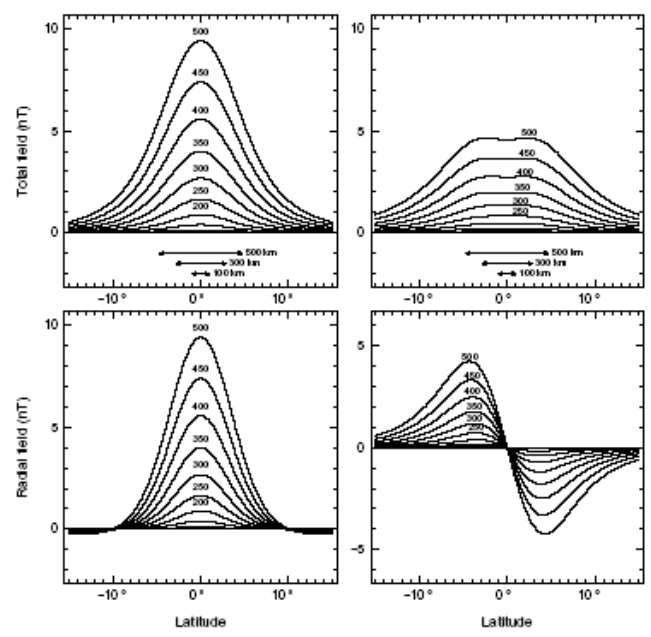



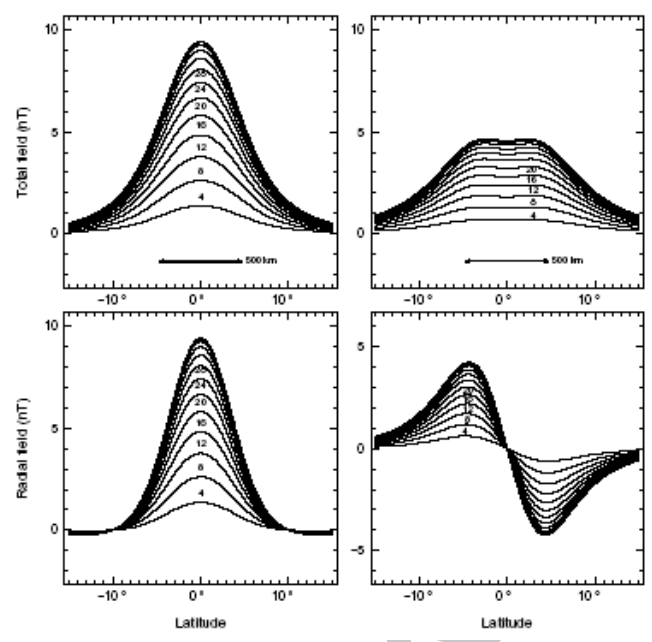


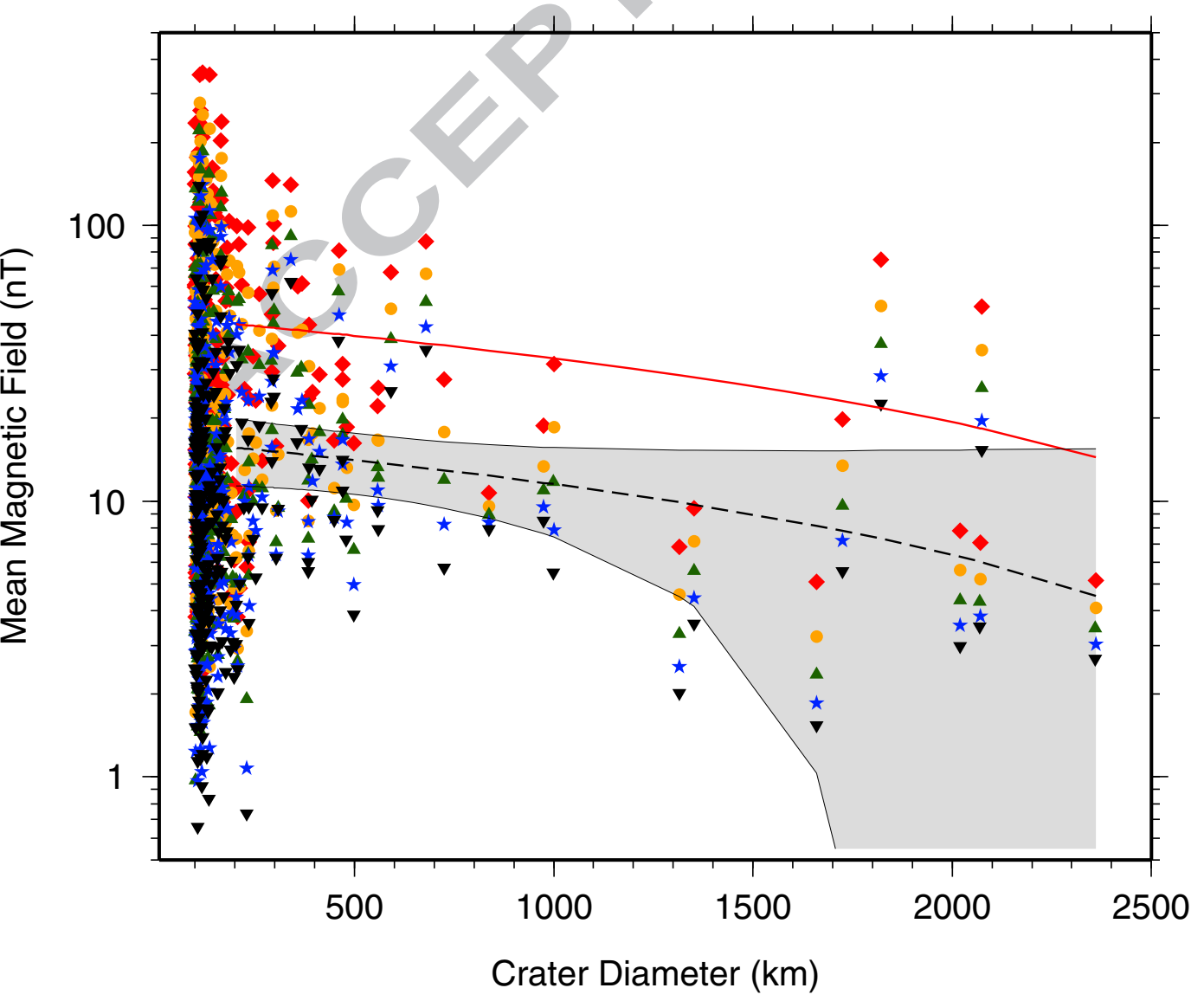




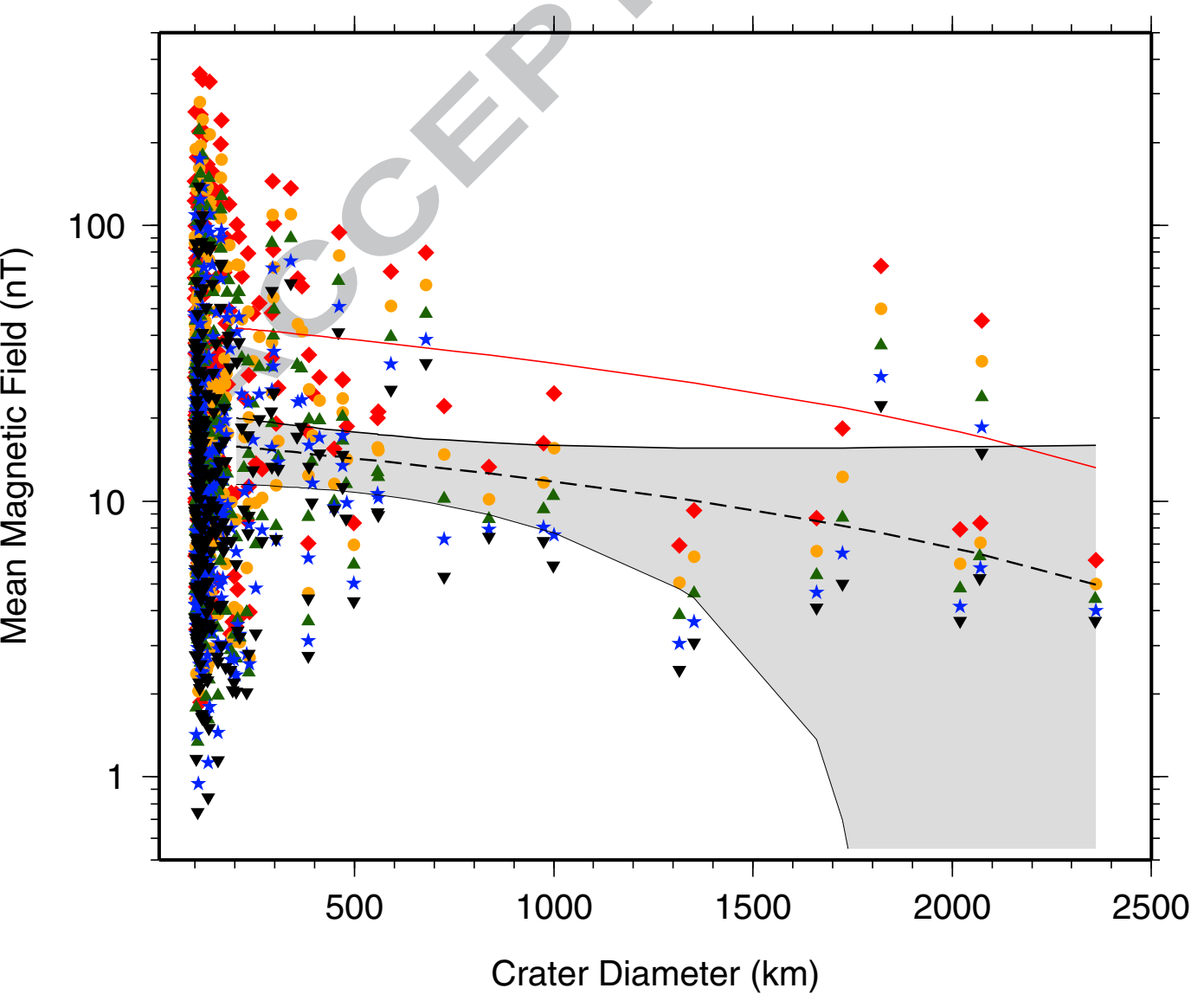


- Forward approach allows to predict the magnetic signature of impact craters;

- MGS magnetic data are used to estimate true magnetic field above craters;

- Craters as small as $200-\mathrm{km}$ have significant signatures at $400-\mathrm{km}$ altitude

- These could be used for timing the dynamo cessation

- This highlights the need for complementary measurements 